\title{
Project 90252
}

Calix[4]arenebiscrown-6 molecules are currently the selected technology for removal of radioactive cesium-137 from DOE nuclear wastes. By attachment of an acidic function to such molecules, the efficiency with which cesium ion can be extracted from an aqueous solution into an organic diluent is markedly increased since the requirement for concomitant extraction of an aqueous phase anion is avoided. Thus, cesium ion extraction by proton-ionizable calix[4] arenebiscrown-6 molecules may be the "secondgeneration" technology for removal of cesium-137 from DOE nuclear wastes. During Year 1 of this EMSP project, we have established synthetic routes to new, lipophilic, proton-ionizable calix[4]arenebiscrown-6 molecules to be evaluated for solvent extraction of cesium ion at Oak Ridge National Laboratory. Analogous calix[4]arenecrown-6 compounds are also being prepared to determine if even higher cesium ion selectivities can be obtained with extractants having a single crown ether unit. 